\title{
Neonatal shaken baby syndrome: an aetiological view from Down Under
}

\section{A N Williams, R Sunderland}

\section{The potential dangers of vigorous chest physiotherapy in premature infants have not been widely communicated}

$\mathrm{H}$ owever hard we may strive to be up to date in our medical specialty, we are limited by the material we have to hand. There are the twin difficulties of ever increasing medical publication and disseminating crucial information to a wider critical readership. Sometimes though, in an unrelated area of medicine, new information occurs that illuminates other fields. This not only informs but may guide future practice. The controversy about vigorous chest physiotherapy for extreme preterm infants may have wider implications for professionals concerned with child protection.

In the 1990s there was a debate about strategies to prevent chronic lung disease in the extreme premature infant. The use of vigorous chest physiotherapy became the subject of an official enquiry by the New Zealand Ministry of Health, ${ }^{1}$ which appears largely unknown to paediatricians and neonatologists in the Northern Hemisphere. The New Zealand Group report difficulty in publishing their findings until 1998. ${ }^{2}$ A Cochrane review in this area was last updated in $1997 .^{3}$

Between 1988 and 1990, postnatal encephaloclastic porencephaly (ECPE), a new and previously unrecognised distinctive pattern of brain injury, was seen in an English neonatal unit. This was strikingly different from previously seen neonatal brain injury as it presented late in the neonatal period with extensive bilateral, full thickness cortical necrosis (deaths occurred at between 13 and 42 days of age). No cause was identified: 14 of the 15 cases described were fatal, and the sole survivor had a severe neurological deficit at 12 months of age. The English neonatologists, in a review of their practice, recognised the similarities between ECPE and shaking injuries in older children. They changed physiotherapy management so that the infant's head was held steady during the procedure, and subsequently there was a rapid reduction in incidence of ECPE. ${ }^{5}$ They were unable to identify any other factor that could have been responsible.

Between 1992 and 1994, neonatologists in New Zealand noted a cluster of 13 cases of severe and unusual brain damage, which in retrospective had the same pathological features as ECPE. An initial case controlled study of 50 putative factors identified no causative association. A second study noted that all affected infants were extremely premature, were more likely to have prolonged severe hypotension and a decreased likelihood of cephalic presentation, and had received vigorous frequent chest physiotherapy to reduce the risk of chronic lung disease. ${ }^{2}$ There was a temporal association between the onset of ECPE and the introduction of the rigorous physiotherapy regimen, although three cases had occurred before the official policy of vigorous physiotherapy was formally introduced. After an embargo on vigorous chest physiotherapy for extreme premature infants, there were no cases of ECPE. Subsequent analysis identified no change in the other risk factors.

Thus two eminent neonatal units had recognised an association between ECPE and vigorous chest physiotherapy with disappearance on change in practice (cessation in New Zealand, holding the head in England).

In 1999 the New Zealand Ministry of Health commissioned an enquiry to determine whether injury sustained by babies after receiving physiotherapy constituted medical error. The 200 page report ${ }^{1}$ provides salutary information for all doctors.

With regard to the brain injury, clinicians and pathologists commented that there was a striking similarity between the lesion in the premature infant brain and that seen in older children caused by violent shaking. ${ }^{12}$ The commission noted that the implications of supporting of the head during chest physiotherapy in England were not communicated to the medical community nor was this caution written into hospital protocols. ${ }^{1}$ The New Zealand paediatricians told the Commission that they were unaware of the effect of changing practice until they telephoned the English authors in late 1994 and, as a consequence, introduced their embargo.

Differing opinions were expressed by two expert witnesses:

“. . . in shaking baby syndrome I would discount it because I think it has been clearly established that it requires more than that. I could not discount it in ECPE because I think the immaturity of the brain makes it an entirely different situation."

"I have great difficulty in accepting the analogy [between shaken baby syndrome and ECPE] because I think the difference is so great, but I acknowledge that the temporal association with stopping the physiotherapy and disappearing is a strong one and the physiotherapy may well be related to the ECPE."

During the inquiry, many parents gave evidence of their children being shaken and their concerns.

“. . banging the baby's chest with the baby shaking like a jelly on a plate... We are told never to shake a baby and yet here it was happening in hospital."

“ . . my baby was bouncing around on the bed and the head and parts of the body which were not restrained were all moving, it was like they were on a little trampoline."

"The baby's head would move a lot, it looked to me as though the baby had little spasms running through the body."

"because I had complete trust in the doctors, nurses and physiotherapists, I did not query the treatment."

There has been no suggestion that any of the professional staff intended to harm these infants. Subsequent recognition that vigorous chest physiotherapy without supporting the head in premature infants may lead to a lethal shaken brain injury does not appear to have been widely discussed among forensic paediatricians. The brain becomes more viscous with maturation which renders it less vulnerable to sheering forces. The minimum forces required to cause shaken brain injuries are not known, there being a paucity of observed information. It is also impossible on ethical grounds to conduct the experiments necessary to obtain an answer. The physiotherapy practices discussed in this official report may be an important insight.

Arch Dis Child Fetal Neonatal Ed 2002;86: F29-F30

\section{Authors' affiliations}

A N Williams, Orchard Centre for Community Health, Rugby, North Warwickshire NHS Trust UK

R Sunderland, Birmingham Childrens'

Hospital, Steelhouse Lane, Birmingham B4 $6 \mathrm{NH}, \mathrm{UK}$ 
Correspondence to: Dr Sunderland, Birmingham Childrens' Hospital, Steelhouse Lane, Birmingham B4 6NH, UK;

r.sunderland@bham.ac.uk

\section{REFERENCES}

1 Cull H, Weston P, Adams J. Enquiry into provision of chest physiotherapy treatment provided to preterm babies at National Women's Hospital between April 1993 and December 1994. Wellington: Ministry of Health, 1999 (ISBN 0-478-23556-9).

2 Harding JE, Miles FKI, Becroft DMO, et al. Chest physiotherapy may be associated with brain damage in extremely premature infants. J Pediatr 1998;132:440-4.

3 Flenady VJ, Gray PH. Chest physiotherapy for preventing morbidity in babies being extubated from mechanical ventilation. The Cochrane Library. Oxford: Update Software, 2000:issue 4.

4 Cross JH, Harrison CJ, Preston PR, et al. Postnatal encephaloclastic porencephaly: a new lesion? Arch Dis Child 1992;67:307-1 1

5 Coney S. Physiotherapy technique banned in Auckland. Lancet 1995;345:510.

\section{ADDENDUM}

Since we submitted this article, Knight et al ${ }^{1}$ from the National Women's Hospital, Auckland published a review of chest physiotherapy between 1985 and 1998 looking at ECPE in a population of 2219 premature babies weighing less than $1500 \mathrm{~g}$. There were no new cases of ECPE other than the 13 cases reported between 1992 and 1994. The authors found no association between the number of chest physiotherapy treatments and ECPE. There were, however, few data on the vigour of individual treatments. The incidence of other identified risk factors (early hypotension and non-cephalic presentation) did not alter. However, the authors admit that there was no policy to support the head during chest physiotherapy and no data on the extent the head moved during physiotherapy. Review of brain histology was "consistent with shaking injury in the immature brain". They postulate that chest physiotherapy was a cause of ECPE, the proposed mechanism of injury being "greater head movements during chest percussion".

\section{REFERENCE}

1 Knight DB, Bevan CJ, Harding JE, et al. Chest physiotherapy and porencephalic lesions in very preterm infants. J Paediatr Child Health 2001;37:554-8.

\section{COMMENTARY}

When papers that are controversial or subjective or both are accepted for publication in the Journal, we are told by the editors that a simultaneously published commentary is an effective way of contributing to discussion. Within that context, there are several issues raised in this paper that are of concern to us.

The first is its lack of topicality. There have been only two published series describing postnatal ECPE. They were published in 1992 and 1998. ${ }^{2}$ There have been no subsequent publications nor has it been our experience or, so far as we can ascertain from extensive discussion with colleagues, the experience of others that the brain lesions described in these papers and commented upon by Williams and Sunderland are an entity in their own right.

This lack of discussion on relevant or possible neuropathological mechanisms is of concern to us when aetiological speculation forms a substantial part of the paper of Williams and Sunderland. Their implication, although it is not made clear in either their text or any of the papers they cite as references, is that very sick preterm infants have the potential to sustain shearing injuries of their brains if they are subjected to vigorous neonatal chest physiotherapy without their heads being stabilised.

There is, however, no corroboration that the brain lesions reported in these studies were in fact shearing injuries, and, given the multifactorial aspects of brain vulnerability in very ill preterm children, it is hard to accept that they were in effect "shaking" injuries. Hence, if this issue is going to be appropriately revisited, we would like to see the neuropathology considered by specialists in neonatal pathology and paediatric neuroradiology before accepting the assumed causes of the brain injuries.

Our second major concern relates to the implication that neonatal physiotherapy for preterm infants with chest disease has a component of "shaking" or other vigorous handling of the infant. This is just not so. There is an abundant literature, recently brought up to date by
Flenady and Gray, ${ }^{3}$ which not only details the appropriate treatments but also confirms that under these circumstances brain damage is not seen.

It is also appropriate to remind Williams and Sunderland that papers on the appropriateness and effectiveness of physiotherapy in preterm children, with the demonstration that it is safe and useful, go back as far as $1978^{4}$ and $1980 .{ }^{5}$ Hence, for the authors to state that there is no or limited awareness of which are the appropriate physiotherapy techniques to use in sick preterm infants is not an accurate representation of the current state of practice.

Our third major criticism of this paper relates to what purports to be its wider message or rather its mixed messages. The scapegoating of health professionals by media and politicians is fashionable, and the penumbra of this process extends way beyond any appropriate targets. We can certainly testify to that from experience in our own centre. Our anxiety about this paper is that the authors are effectively encouraging unfounded criticism of physiotherapy. They do this by describing a practice that is not undertaken, but, by writing about it imply that it is, and moreover that it is recognised as causing brain damage to infants. Please could we have a more systematic, rational, and objective approach to difficult clinical problems than that offered in this paper.

L Rosenbloom

S Ryan

Royal Liverpool Children's NHS Trust, Alder Hey Hospital, Liverpool L12 2 AP, UK

Arch Dis Child Fetal Neonatal Ed 2002;86: F30

\section{REFERENCES}

1 Cross JH, Harrison CJ, Preston PR, et al. Postnatal encephaloplastic porencephaly: a new lesion? Arch Dis Child 1992:67:307-11.

2 Harding JE Miles FKI, Becroft DMO et al. Chest physiotherapy may be associated with Chest physiotherapy may be associated with brain damage in extremely

3 Flenady VJ, Gray PH. Chest physiotherapy for preventing morbidity in babies being extubated from mechanical ventilation. The Cochrane Library. Oxford: Update Software, 2000:issue 4

4 Finer N, Boyd J. Chest physiotherapy in the neonate: a control study. Pediatrics 1978:61:282-5.

5 Tudehope DI, Bagley C. Techniques of physiotherapy in intubated babies with respiratory distress syndrome. Aust Paediatr J 1980;16:226-8 